Article

\title{
Correlation Coefficients of Probabilistic Hesitant Fuzzy Elements and Their Applications to Evaluation of the Alternatives
}

\author{
Zhong-xing Wang ${ }^{1}$ and Jian $\mathrm{Li}^{2, *}$ \\ 1 School of Mathematics and Information Science, Guangxi University, Nanning 530004, China; \\ zxwgx@126.com \\ 2 School of XingJian College of Science and Liberal Arts, Guangxi University, Nanning 530005, China \\ * Correspondence: jian2016@csu.edu.cn
}

Received: 25 September 2017; Accepted: 29 October 2017; Published: 2 November 2017

\begin{abstract}
Correlation coefficient is one of the broadly use indexes in multi-criteria decision-making $(\mathrm{MCDM})$ processes. However, some important issues related to correlation coefficient utilization within probabilistic hesitant fuzzy environments remain to be addressed. The purpose of this study is introduced a MCDM method based on correlation coefficients utilize probabilistic hesitant fuzzy information. First, the covariance and correlation coefficient between two PHFEs is introduced, the properties of the proposed covariance and correlation coefficient are discussed. In addition, the northwest corner rule to obtain the expected mean related to the multiply of two PHFEs is introduced. Second, the weighted correlation coefficient is proposed to make the proposed MCDM method more applicable. And the properties of the proposed weighted correlation coefficient are also discussed. Finally, an illustrative example is demonstrated the practicality and effectiveness of the proposed method. An illustrative example is presented to demonstrate the correlation coefficient propose in this paper lies in the interval $[-1,1]$, which not only consider the strength of relationship between the PHFEs but also whether the PHFEs are positively or negatively related. The advantage of this method is it can avoid the inconsistency of the decision-making result due to the loss of information.
\end{abstract}

Keywords: probabilistic hesitant fuzzy element; covariance; correlation coefficient; northwest corner rule; multi-criteria decision-making

\section{Introduction}

With the rapid development of economic and the progress of modern society, people are facing more and more complicated decision-making problems, group decision-making plays an increasingly important role when dealing with multi-criteria decision-making (MCDM) problems [1-3]. In our daily life, group decision-making has turned out to be a commonly used tool in human activities, whose purpose is to determine the most preferred alternative among several alternatives (or a series of alternatives) using the evaluation values provided from a group of decision makers. In group decision-making processes, the information provided by the experts has different forms. Because of this, many scholars have investigated the techniques based on various kinds of decision information, including intuitionistic fuzzy sets [4,5], hesitant fuzzy sets (HFSs) [6-8], probabilistic hesitant fuzzy sets (PHFSs) $[9,10]$ and probabilistic linguistic term sets [11] and so on.

Correlation coefficient is one of the broadly use indexes in MCDM processes [12-14]. Since many data may be fuzzy and uncertain, the utilization of correlation coefficient has been extended to fuzzy environments [15-17] and intuitionistic fuzzy environments [18-21]. For example, Huang et al. [18] proposed a correlation coefficient formula utilizing the centroid of intuitionistic fuzzy numbers. Ye [19] 
utilizing entropy weights of intuitionistic fuzzy numbers proposed the weighted correlation coefficient. In a sequent, Dong et al. [21] proposed weighted correlation coefficient based on the relationship of an arbitrary alternative and the ideal alternative. Afterwards, correlation coefficient has been extended to hesitant fuzzy environments [22-25]. At the same time, some correlation coefficients formulas have been proposed. Such as, Chen et al. [22] derived some correlation coefficients based on the membership degree of the HFSs and applied them in clustering analysis. Liao et al. [23] pointed out there are some shortcoming in the correlation coefficients were introduced in [22] and then proposed a novel correlation coefficient. The significant characteristic of the proposed formula is that it lies in the interval $[-1,1]$. Based on the same idea, Liao et al. [24] proposed several types of correlation coefficients for hesitant fuzzy linguistic term sets and then applied them to traditional medical diagnosis problems. Because of the potential application of the correlation coefficient, some other extensions are still going on-for example, dual hesitant fuzzy environments [26] and neutrosophic fuzzy environments [27-29] and so on.

Although the concept of correlation coefficient has been extended to various kinds of fuzzy environments and has been applied in many fields. There are still some disputes in the utilization of it. Some decision makers noticed that the correlation coefficients were proposed in above mention papers mainly lies on the statistics formula, that is, the correlation coefficient between two random variables $X$ and $Y$ is $\rho(X, Y)=\frac{E(X-E(X))(Y-E(Y))}{\sqrt{D(X)} \sqrt{D(Y)}}$. In addition, the correlation coefficient has lots of important properties, such as lies in the range of $[-1,1]$. Unfortunately, most of the correlation coefficients in above mention papers always positive, which lies in the range of $[0,1]$ and ignored the negative correlation information. This shortcoming has been pointed out by some scholars $[18,23,25]$ and the ignored information may result in unreasonable decision-making results. Based on this consideration, the correlation coefficient be applied in fuzzy environment should be further discussion.

Since Zhu [30] first proposed the concept of PHFSs, it has been attracted some scholars' attention and many achievements have been made. For example, Zhang et al. [31] pointed out that there are some shortcoming in the concept of PHFSs that was proposed in [30], they asserted that there were maybe some incomplete information in the decision-making processes and then they proposed the improvement PHFSs. He et al. [32] extended the PHFSs to the probabilistic interval preference ordering sets and Hao et al. [33] extended it to the probabilistic dual hesitant fuzzy sets. In addition, PHFSs have been extended to probabilistic linguistic term sets [11,34,35]. Although the concept of PHFSs has been extended to various kinds of fuzzy environments and some decision-making methods have been proposed. For example, Zhou et al. [36] discussed group consensus based on additive consistency and Li et al. [9] introduced a MCDM process based on Hausdorff distance. However, some important issues in PHFSs utilization remain to be addressed. For example, the probability part does not pay enough attention, the existing decision-making methods mainly directly integrated the probability part into the membership degree part [9,36], this make cause a lot of information loss.

Considering that PHFSs consists of two parts, that is, the membership degree of the elements to the set and the corresponding probabilities of the membership degree, this information can be interpreted as a probability distribution function. Inspired by statistics knowledge, each probabilistic hesitant fuzzy element (PHFE) can be treated as a discrete random variable. Since every PHFE has two parts, that is: $\gamma_{i}$ and $p_{i}$, where $\gamma_{i}$ can be regarded as the condition of a random variable, $p_{i}$ can be regarded as the corresponding probability with $\gamma_{i}$, the similar opinion has been proposed by Hung [37]. Based on this consideration, we can apply some concepts in statistics such as expected value, variance, covariance and correlation coefficient, to construct a novel MCDM method within the background of a probabilistic hesitant environment. Considering sometimes two random variables maybe do not mutual independent. In this paper, the expected mean related to the multiply of two PHFEs can be obtained through using the northwest corner rule, from the course of operations research, balance problems of transport model [38].

To overcome the above mention limitations, this paper focuses on the correlation coefficient between two PHFSs and based on the northwest corner rule to obtain the expected mean related to the 
multiply of two PHFEs when the PHFEs are not mutual independent. Finally, a novel MCDM method with the probabilistic hesitant fuzzy environment is introduced based on the proposed weighted correlation coefficient. The primary motivations and contributions of this paper are summarized as follows.

(1) A novel formula to calculate the correlation coefficient between two PHFSs is proposed. The correlation coefficient is proposed in this paper utilize the knowledge of statistics, the significant characteristic of the proposed formula is that it lies in the interval $[-1,1]$. The proposed formula not only consider the strength of the PHFSs but also whether the PHFSs are positively or negatively related, it avoids the inconsistency of the decision-making result due to the loss of information.

(2) The existing decision-making methods within probabilistic hesitant fuzzy environments, few papers discussed the condition when two PHFEs are not mutual independent. In this paper, the northwest corner rule to obtain the expected mean related to the multiply of two PHFEs is introduced.

(3) A novel MCDM method within the probabilistic hesitant fuzzy environment is introduced based on the proposed weighted correlation coefficient and this proposed method is applied to practical decision-making problems, that is, the evaluation of the alternatives.

The rest of this paper is organized as follows. Section 2 reviews some basic concepts related to HFSs and PHFSs and some correlation coefficient formulas related to HFSs. In Section 3, we introduce a novel correlation coefficient formula for PHFSs, the properties of the proposed covariance and correlation coefficient are discussed. And the northwest corner rule to obtain the expected mean related to the multiply of two PHFEs is introduced. In Section 4, the weighted correlation coefficient is proposed and the properties of the proposed weighted correlation coefficient are discussed. The weighted correlation coefficient of two PHFEs is applied to an evaluation of the alternatives problem in Section 5. Finally, the conclusions are given in Section 6.

\section{Preliminaries}

In this section, several basic definitions and notations related to our research will be reviewed, mainly including HFS, correlation coefficient and the concept of PHFS, its score function and indeterminacy index function. In addition, an evaluation information integrate method is introduced.

Definition 1. [39] Let $X$ be a reference set, a HFS $A$ on $X$ is defined in terms of a function $h_{A}(x)$ when applied to $X$ returns a finite subset of $[0,1]$.

To be easily understand, Xia et al. [40] expressed the HFS by a mathematical symbol:

$$
A=\left\{<x, h_{A}(x)>\mid x \in X\right\} .
$$

Here, the function $h_{A}(x)$ is a set of some different values in $[0,1]$, representing the possible membership degrees of the element $x$ in $X$ to $A$. For convenience, $h_{A}(x)$ is called a HFE.

Example 1. Let $X=\left\{x_{1}, x_{2}, x_{3}\right\}$ be a reference set, $h_{A}\left(x_{1}\right)=\{0.2,0.4,0.6\}, h_{A}\left(x_{2}\right)=\{0.3,0.4,0.5\}$ and $h_{A}\left(x_{3}\right)=\{0.2,0.3,0.5,0.6\}$.

Be three HFEs of $x_{i}(i=1,2,3)$ to a set $A$, respectively. Then $A$ can be considered as a HFS,

$$
A=\left\{\left\langle x_{1},\{0.2,0.4,0.6\}\right\rangle,\left\langle x_{2},\{0.3,0.4,0.5\}\right\rangle,\left\langle x_{3},\{0.2,0.3,0.5,0.6\}\right\rangle\right\} .
$$

Correlation coefficient is a frequently use formulas and has been applied in measure the similarity between two objects. Liao et al. [23] defined the correlation coefficient between two HFSs as follows. 
Definition 2. [23] Let $X=\left\{x_{1}, x_{2}, \cdots, x_{n}\right\}$ be a discrete universe of discourse and $F^{i}$ be the hesitant fuzzy space containing all HFSs defined over X. For any two HFSs, $h_{A}\left(x_{i}\right)=\left\{\gamma_{A_{i 1}}, \gamma_{A_{i 2}}, \cdots, \gamma_{A_{i l}}\right\}$ and $h_{B}\left(x_{i}\right)=\left\{\gamma_{B_{i 1}}, \gamma_{B_{i 2}}, \cdots, \gamma_{B_{i l_{B}}}\right\}$, the correlation coefficient between them is defined as follows:

$$
\rho(A, B)=\frac{\operatorname{Cov}(A, B)}{[D(A) D(B)]^{1 / 2}}
$$

where

$$
\begin{gathered}
\operatorname{Cov}(A, B)=\frac{1}{n} \sum_{i=1}^{n}\left[\bar{h}_{A}\left(x_{i}\right)-\bar{A}\right] \cdot\left[\bar{h}_{B}\left(x_{i}\right)-\bar{B}\right], \\
D(A)=\frac{1}{n} \sum_{i=1}^{n}\left[\bar{h}_{A}\left(x_{i}\right)-\bar{A}\right] \cdot\left[\bar{h}_{A}\left(x_{i}\right)-\bar{A}\right], \\
D(B)=\frac{1}{n} \sum_{i=1}^{n}\left[\bar{h}_{B}\left(x_{i}\right)-\bar{B}\right] \cdot\left[\bar{h}_{B}\left(x_{i}\right)-\bar{B}\right] .
\end{gathered}
$$

and, $\bar{h}_{A}\left(x_{i}\right)=\frac{1}{l_{A_{i}}} \sum_{k=1}^{l_{A_{i}}} \gamma_{A_{i k}}, \bar{h}_{B}\left(x_{i}\right)=\frac{1}{l_{B_{i}}} \sum_{k=1}^{l_{B_{i}}} \gamma_{B_{i k}}, \bar{A}=\frac{1}{n} \sum_{i=1}^{n} \bar{h}_{A}\left(x_{i}\right)$ and $\bar{B}=\frac{1}{n} \sum_{i=1}^{n} \bar{h}_{B}\left(x_{i}\right)$. Where $l_{A_{i}}$ and $l_{B_{i}}$ are respectively denotes the number of the elements in $h_{A}\left(x_{i}\right)$ and $h_{B}\left(x_{i}\right)$.

Recently, Zhang et al. [31] proposed the improvement of PHFSs, which have added the partial ignorance information to PHFSs that was proposed by Zhu [30].

Definition 3. [31] Let $X$ be a reference set, then a PHFS P on $X$ can be expressed by as:

$$
P=\left\{<x, h_{x}\left(p_{x}\right)>\mid x \in X\right\} .
$$

Here, the function $h_{x}$ is a set of several different values in $[0,1]$, which is described by the probability distribution $p_{x}$. Where $h_{x}$ denotes the possible membership degree of element ${ }_{x}$ in $X$ to $P$. For convenience, $h_{x}\left(p_{x}\right)$ is called a PHFE and denoted as $h(p)$ and is indicated by

$$
h(p)=\left\{\gamma_{i}\left(p_{i}\right)|i=1,2, \cdots,| h(p) \mid\right\},
$$

where $p_{i}$ satisfying $\sum_{i=1}^{|h(p)|} p_{i} \leq 1$, is the probability of the possible value $\gamma_{i}$ and $|h(p)|$ is the number of all $\gamma_{i}\left(p_{i}\right)$ in $h(p)$. If $\sum_{i=1}^{|h(p)|} p_{i}<1$, means there is some missing values in PHFE. If there is no special explanation, in this paper, we only discuss the condition $\sum_{i=1}^{|h(p)|} p_{i}=1$.

Example 2. Let $X=\left\{x_{1}, x_{2}\right\}$ be a reference set, $h_{1}\left(p_{1}\right)=\{0.2(0.3), 0.4(0.2), 0.5(0.1), 0.7(0.4)\}$ and $h_{2}\left(p_{2}\right)=\{0.3(0.1), 0.4(0.9)\}$ be two PHFEs of $x_{i}(i=1,2)$ to a set $P$, respectively. Then $P$ can be considered as a PHFS,

$$
P=\left\{\left\langle x_{1},\{0.2(0.3), 0.4(0.2), 0.5(0.1), 0.7(0.4)\}\right\rangle,\left\langle x_{2},\{0.3(0.1), 0.4(0.9)\}\right\rangle\right\} .
$$

If we ignore the probabilities of the possible values in a PHFE, then the possible values are with the same probability, in this case, PHFE turn to HFE.

In order to rank the PHFEs, $\mathrm{Xu}$ et al. [41] introduced the score function and indeterminacy index function of PHFEs. As a matter of fact, the score function and indeterminacy index function can be regarded as expect mean and variance of PHFEs. 
Definition 4. [41] Let $h_{A}\left(p_{A}\right)=\left\{\gamma_{i}\left(p_{i}\right)|i=1,2, \cdots| h,(p) \mid\right\}$ be a PHFE, the expect mean of it is defined as:

$$
E(A)=\sum_{i=1}^{|h(p)|} \gamma_{i} p_{i}
$$

It is noted that if the probabilities of PHFE are equally, that is $p_{1}=p_{2}=\cdots=p_{|h(p)|}=\frac{1}{|h(p)|}$, in this case, expect mean will turn to the score function of HFS that was introduced in Definition 4 in [40].

Definition 5. [41] Let $h_{A}\left(p_{A}\right)=\left\{\gamma_{i}\left(p_{i}\right)|i=1,2, \cdots| h,(p) \mid\right\}$ be a PHFE, the variance of it is defined as:

$$
D(A)=\sum_{i=1}^{|h(p)|}\left(\gamma_{i}-E(A)\right)^{2} p_{i}
$$

Example 3. Let $h_{A}\left(p_{A}\right)=\{0.5(0.25), 0.6(0.5), 0.7(0.25)\}$ be a PHFE, according to Definition 4 and Definition 5 , we have $E(A)=0.5 \times 0.25+0.6 \times 0.5+0.7 \times 0.25=0.6, D(A)=(0.5-0.6)^{2} \times 0.25+$ $(0.6-0.6)^{2} \times 0.5+(0.7-0.6)^{2} \times 0.25=0.005$.

Remark 1. If there is only one element in a PHFE, in this case, we have $D(A)=0$.

Remark 2. According to statistics knowledge, there is an equivalence formula related to the variance of $h_{A}\left(p_{A}\right)$ in Definition 5, that is:

$$
D(A)=\sum_{i=1}^{|h(p)|} \gamma_{i}^{2} p_{i}-E(A)^{2}
$$

In order to integrate the evaluation information obtained from decision makers in the decision-making processes, according to the total probability formula in statistics, Li et al. [42] introduced an information integrate method as follows.

Definition 6. [42] For a reference set $X$, let $P=\left\{\left\langle x, h_{x}\left(p_{x}\right) \mid x=1,2, \cdots, n\right\rangle\right\}$ be a PHFS, where $h(p)=$ $\left\{\gamma_{i}\left(p_{i}\right)|i=1,2, \cdots| h,(p) \mid\right\}$ is the PHFE indicating all possible values in $P$. Then, the probability of the value $\gamma_{i}$ can be calculated as follows:

$$
P\left(x=\gamma_{i}\right)=\sum_{i=1}^{n} P(x=h(p)) P\left(x=\gamma_{i} / x=h(p)\right),
$$

where $n$ is the number of all PHFEs in $P$.

Example 4. Let $P=\left\{\left\langle x_{1},\{0.4(0.6), 0.6(0.3), 0.7(0.1)\}\right\rangle,\left\langle x_{2},\{0.3(0.7), 0.4(0.3)\}\right\rangle,\left\langle x_{3},\{0.8(0.2), 0.9(0.8)\}\right\rangle\right\}$ be a PHFS. The probability of value 0.4 in $P$ is calculated as follows: $P(x=0.4)=\frac{1}{3} \times 0.6+\frac{1}{3} \times 0.3+\frac{1}{3} \times 0=0.3$.

\section{The Correlation Coefficient of PHFEs}

Since every PHFE has two parts, that is: $\gamma_{i}$ and $p_{i}$, where $\gamma_{i}$ can be regarded as the condition of a random variable, $p_{i}$ can be regarded as the corresponding probability of $\gamma_{i}$. Based on this consideration, every PHFE can be regarded as a discrete random variable. In the following section, covariance and the correlation coefficients of PHFEs will be introduced.

In order to obtain the correlation coefficients of PHFEs. First, the standard deviation of it is calculated. Second, the expect value related to the multiple of two PHFEs is calculated. Then, the covariance of the PHFEs is obtained. Finally, based on the standard deviation and covariance, the correlation coefficient of PHFEs can be obtained.

According to the statistics knowledge, the standard deviation of PHFEs can be obtained from the square of the deviation. And in order to obtain the expect value related to the multiply of $A B$, that is, 
PHFE $h_{A}\left(p_{A}\right)$ multiply PHFE $h_{B}\left(p_{B}\right)$. First, the joint distribution law between $h_{A}\left(p_{A}\right)$ and $h_{B}\left(p_{B}\right)$ will be determined and then based on the joint distribution law, we can calculate the expect value related to the multiply of $A B$. Considering sometimes two PHFEs maybe do not mutual independent, in the following section, a method to determine the joint distribution law between $h_{A}\left(p_{A}\right)$ and $h_{B}\left(p_{B}\right)$ will be introduced.

Let $h_{A}\left(p_{A}\right)=\left\{\gamma_{i}\left(p_{i}\right)|i=1,2, \cdots| h,(p) \mid\right\}$ and $h_{B}\left(p_{B}\right)=\left\{\gamma_{j}^{\prime}\left(p_{j}^{\prime}\right)|j=1,2, \cdots| l,(p) \mid\right\}$ be two PHFEs, utilizing the northwest corner rule [38], the joint distribution law between $h_{A}\left(p_{A}\right)$ and $h_{B}\left(p_{B}\right)$ can be determined and is shown in Table 1.

Where $\sum_{j=1}^{|l(p)|} p_{i j}=p_{i},(i=1,2, \cdots,|h(p)|)$ and $\sum_{i=1}^{|h(p)|} p_{i j}=p_{j}^{\prime},(j=1,2, \cdots,|l(p)|)$ and $|h(p)|$ and $|l(p)|$ are respectively denotes the number of the elements in $h_{A}\left(p_{A}\right)$ and $h_{B}\left(p_{B}\right)$.

Base on the joint distribution law, expect value related to the multiply of $A B$ can be obtained as follows.

Table 1. Joint distribution law between $h_{A}\left(p_{A}\right)$ and $h_{B}\left(p_{B}\right)$.

\begin{tabular}{cccccccc}
\hline & $\gamma_{1}^{\prime}$ & $\gamma_{2}^{\prime}$ & $\cdots$ & $\gamma_{j}^{\prime}$ & $\cdots$ & $\gamma_{|l(p)|}^{\prime}$ & $p_{i} \cdot$ \\
\hline$\gamma_{1}$ & $p_{11}$ & $p_{12}$ & $\cdots$ & $p_{1 j}$ & $\cdots$ & $p_{1|l(p)|}$ & $p_{1}$ \\
$\gamma_{2}$ & $p_{21}$ & $p_{22}$ & $\cdots$ & $p_{2 j}$ & $\cdots$ & $p_{2|l(p)|}$ & $p_{2}$ \\
$\vdots$ & $\vdots$ & $\vdots$ & $\vdots$ & $\vdots$ & $\vdots$ & $\vdots$ & $\vdots$ \\
$\gamma_{i}$ & $p_{i 1}$ & $p_{i 2}$ & $\cdots$ & $p_{i j}$ & $\cdots$ & $p_{i|l(p)|}$ & $p_{i}$ \\
$\vdots$ & $\vdots$ & $\vdots$ & $\vdots$ & $\vdots$ & $\vdots$ & $\vdots$ & $\vdots$ \\
$\gamma_{|h(p)|}$ & $p_{|h(p)| 1}$ & $p_{|h(p)| 2}$ & $\cdots$ & $p_{|h(p)| j}$ & $\cdots$ & $p_{|h(p)||l(p)|}$ & $p_{|h(p)|}$ \\
$p_{\cdot j}$ & $p_{1}^{\prime}$ & $p_{2}^{\prime}$ & $\cdots$ & $p_{j}^{\prime}$ & $\cdots$ & $p_{|l(p)|}^{\prime}$ & 1 \\
\hline
\end{tabular}

Definition 7. Let $h_{A}\left(p_{A}\right)=\left\{\gamma_{i}\left(p_{i}\right)|i=1,2, \cdots| h,(p) \mid\right\}$ and $h_{B}\left(p_{B}\right)=\left\{\gamma_{j}^{\prime}\left(p_{j}^{\prime}\right)|j=1,2, \cdots| l,(p) \mid\right\}$ be two PHFEs, then expect value related to the multiply of $A B$ is calculated as:

$$
E(A B)=\sum_{i=1}^{|h(p)|} \sum_{j=1}^{|l(p)|} \gamma_{i} \gamma_{j}^{\prime} p_{i j} .
$$

Example 5. Let $h_{A}\left(p_{A}\right)=\{0.5(0.25), 0.6(0.5), 0.7(0.25)\}$ and $h_{B}\left(p_{B}\right)=\{0.2(0.25), 0.3(0.75)\}$ be two PHFEs, utilizing the northwest corner rule, the joint distribution law between $h_{A}\left(p_{A}\right)$ and $h_{B}\left(p_{B}\right)$ can be determined and is shown in Table 2.

Table 2. Joint distribution law between $h_{A}\left(p_{A}\right)$ and $h_{B}\left(p_{B}\right)$ of Example 5.

\begin{tabular}{cccc}
\hline & 0.2 & 0.3 & $p_{i} \cdot$ \\
0.5 & 0.25 & 0 & 0.25 \\
0.6 & 0 & 0.5 & 0.5 \\
0.7 & 0 & 0.25 & 0.25 \\
$p \cdot{ }_{j}$ & 0.25 & 0.75 & 1 \\
\hline
\end{tabular}

According to Definition 8, we have $E(A B)=0.5 \times 0.2 \times 0.25+0.6 \times 0.3 \times 0.5+0.7 \times 0.3 \times$ $0.25=0.64$.

Remark 3. If $h_{A}\left(p_{A}\right)=\left\{\gamma_{i}\left(p_{i}\right)|i=1,2, \cdots| h,(p) \mid\right\}$ and $h_{B}\left(p_{B}\right)=\left\{\gamma_{j}^{\prime}\left(p_{j}^{\prime}\right)|j=1,2, \cdots| l,(p) \mid\right\}$ be two mutual independent PHFEs, according to statistics knowledge (the properties of mutual independent discrete random variable), the joint distribution law between $h_{A}\left(p_{A}\right)$ and $h_{B}\left(p_{B}\right)$ can be determined and is shown in Table 3. 
Table 3. Joint distribution law between $h_{A}\left(p_{A}\right)$ and $h_{B}\left(p_{B}\right)$ of Remark 3 .

\begin{tabular}{cccccccc}
\hline & $\gamma_{1}^{\prime}$ & $\gamma_{2}^{\prime}$ & $\cdots$ & $\gamma_{j}^{\prime}$ & $\cdots$ & $\gamma_{|l(p)|}^{\prime}$ & $p_{i} \cdot$ \\
\hline$\gamma_{1}$ & $p_{1} p_{1}^{\prime}$ & $p_{1} p_{2}^{\prime}$ & $\cdots$ & $p_{1} p_{j}^{\prime}$ & $\cdots$ & $p_{1} p_{|l(p)|}^{\prime}$ & $p_{1}$ \\
$\gamma_{2}$ & $p_{2} p_{1}^{\prime}$ & $p_{2} p_{2}^{\prime}$ & $\cdots$ & $p_{2} p_{j}^{\prime}$ & $\cdots$ & $p_{2} p_{|l(p)|}^{\prime}$ & $p_{2}$ \\
$\vdots$ & $\vdots$ & $\vdots$ & $\vdots$ & $\vdots$ & $\vdots$ & $\vdots$ & $\vdots$ \\
$\gamma_{i}$ & $p_{i} p_{1}^{\prime}$ & $p_{i} p_{2}^{\prime}$ & $\cdots$ & $p_{i} p_{j}^{\prime}$ & $\cdots$ & $p_{i} p_{|l(p)|}^{\prime}$ & $p_{i}$ \\
$\vdots$ & $\vdots$ & $\vdots$ & $\vdots$ & $\vdots$ & $\vdots$ & $\vdots$ & $\vdots$ \\
$\gamma_{|h(p)|}$ & $p_{|h(p)|} p_{1}^{\prime}$ & $p_{|h(p)|} p_{2}^{\prime}$ & $\cdots$ & $p_{|h(p)|}^{\prime} p_{j}^{\prime}$ & $\cdots$ & $p_{|h(p)|} p_{|l(p)|}^{\prime}$ & $p_{|h(p)|}$ \\
$p_{\cdot j}$ & $p_{1}^{\prime}$ & $p_{2}^{\prime}$ & $\cdots$ & $p_{j}^{\prime}$ & $\cdots$ & $p_{|l(p)|}^{\prime}$ & 1 \\
\hline
\end{tabular}

Example 6. Let $h_{A}\left(p_{A}\right)$ and $h_{B}\left(p_{B}\right)$ be two PHFEs are shown in Example 5, if $h_{A}\left(p_{A}\right)$ and $h_{B}\left(p_{B}\right)$ are mutual independent, according to Remark 3, the joint distribution law between them can be determined and is shown in Table 4.

Table 4. Joint distribution law between $h_{A}\left(p_{A}\right)$ and $h_{B}\left(p_{B}\right)$ of Example 6 .

\begin{tabular}{cccc}
\hline & 0.2 & 0.3 & $p_{i} \cdot$ \\
0.5 & 0.0625 & 0.1875 & 0.25 \\
0.6 & 0.125 & 0.375 & 0.5 \\
0.7 & 0.0625 & 0.1875 & 0.25 \\
$p \cdot j$ & 0.25 & 0.75 & 1 \\
\hline
\end{tabular}

According to Definition 8, we have $E(A B)=0.0625 \times 0.5 \times 0.2+0.1875 \times 0.5 \times 0.3+0.125 \times$ $0.6 \times 0.2+0.375 \times 0.6 \times 0.3+0.0625 \times 0.7 \times 0.2+0.1875 \times 0.7 \times 0.3=0.165$.

Utilizing Definitions 4 and 7 , the covariance between $h_{A}\left(p_{A}\right)$ and $h_{B}\left(p_{B}\right)$ is obtained as follows.

Definition 8. Let $h_{A}\left(p_{A}\right)=\left\{\gamma_{i}\left(p_{i}\right)|i=1,2, \cdots| h,(p) \mid\right\}$ and $h_{B}\left(p_{B}\right)=\left\{\gamma_{j}^{\prime}\left(p_{j}^{\prime}\right)|j=1,2, \cdots| l,(p) \mid\right\}$ be two PHFEs, the covariance between them is obtained as:

$$
\operatorname{Cov}(A, B)=E(A-E(A))(B-E(B))
$$

The covariance defined in Equation (9) has the following properties.

Property 1. For any PHFEs $h_{A}\left(p_{A}\right)$ and $h_{B}\left(p_{B}\right)$, the covariance defined in Equation (9) satisfies:

(1) $\operatorname{Cov}(A, A)=D(A)$;

(2) $\operatorname{Cov}(A, B)=\operatorname{Cov}(B, A)$;

(3) $\operatorname{Cov}(A, B)=E(A B)-E(A) E(B)$;

(4) If one of the PHFEs has only one element in it, in this case, we have $\operatorname{Cov}(A, B)=0$.

The proof of Property 1 is shown in Appendix A.

Utilizing Definitions 5 and 8, correlation coefficient between two PHFEs is obtained as follows.

Definition 9. Let $h_{A}\left(p_{A}\right)=\left\{\gamma_{i}\left(p_{i}\right)|i=1,2, \cdots| h,(p) \mid\right\}$ and $h_{B}\left(p_{B}\right)=\left\{\gamma_{j}^{\prime}\left(p_{j}^{\prime}\right)|j=1,2, \cdots| l,(p) \mid\right\}$ be two PHFEs, the correlation coefficient between them is obtained as:

$$
\rho(A, B)=\frac{E(A-E(A))(B-E(B))}{\sqrt{D(A)} \sqrt{D(B)}} .
$$

The correlation coefficient obtained in Equation (10) has the following properties. 
Property 2. For any PHFEs $h_{A}\left(p_{A}\right)$ and $h_{B}\left(p_{B}\right)$, the correlation coefficient obtained in Equation (10) satisfies:

(1) $\rho(A, B)=\rho(B, A)$;

(2) $\quad-1 \leq \rho(A, B) \leq 1$;

(3) if $h_{A}\left(p_{A}\right)=h_{B}\left(p_{B}\right) \Rightarrow \rho(A, B)=1$;

(4) if $h_{B}\left(p_{B}\right)=h_{A}\left(p_{A}\right)^{c} \Rightarrow \rho\left(A, A^{c}\right)=-1$.

The proof of Property 2 is shown in Appendix B.

Remark 4. In Property 2, if $h_{A}\left(p_{A}\right)=h_{B}\left(p_{B}\right) \Rightarrow \rho(A, B)=1$, conversely, it is not hold. That is, if $\rho(A, B)=1, \nRightarrow h_{A}\left(p_{A}\right)=h_{B}\left(p_{B}\right)$.

\section{Weighted Correlation Coefficient of PHFEs}

Considering in some situations, the objects may be assigned with different weights. In this section, the weighted form of the expect mean, variance, covariance and correlation coefficient of PHFEs will be introduced.

Let $w=\left(w_{1}, w_{2}, \cdots, w_{n}\right)$ be the weight vector of $x_{i} \in X,(i=1,2, \cdots, n)$ with $w_{i} \in$ $[0,1]$ and $\sum_{i=1}^{n} w_{i}=1$. For two PHFEs $h_{A}\left(p_{A}\right)=\left\{\gamma_{i}\left(p_{i}\right)|i=1,2, \cdots| h,(p) \mid\right\}$ and $h_{B}\left(p_{B}\right)=$ $\left\{\gamma_{j}^{\prime}\left(p_{j}^{\prime}\right)|j=1,2, \cdots| l,(p) \mid\right\}$, the following definitions can be developed.

Definition 10. Let $h_{A}\left(p_{A}\right)=\left\{\gamma_{i}\left(p_{i}\right)|i=1,2, \cdots| h,(p) \mid\right\}$ be a PHFE, the weighted probabilistic hesitant fuzzy element (WPHFE) on $X$ is obtained as:

$$
A_{w}=\left\{\left(w_{i} \gamma_{i}\right)\left(p_{i}\right) \mid i=1,2, \cdots, h(p)\right\} .
$$

Definition 11. Let $A_{w}$ be a WPHFE, the weighted expect mean of it is obtained as:

$$
E_{w}(A)=\sum_{i=1}^{|h(p)|} w_{i} \gamma_{i} p_{i}
$$

Definition 12. Let $A_{w}$ be a WPHFE, the weighted variance of it is obtained as:

$$
D_{w}(A)=\sum_{i=1}^{|h(p)|}\left(w_{i} \gamma_{i}-E_{w}(A)\right)^{2} p_{i}
$$

Let $A_{w}$ and $B_{w^{\prime}}$ be two WPHFEs, utilizing the northwest corner rule, the weight joint distribution law between them can be determined and is shown in Table 5 .

Where $\sum_{j=1}^{|l(p)|} p_{i j}^{\prime}=p_{i},(i=1,2, \cdots,|h(p)|)$ and $\sum_{i=1}^{|h(p)|} p_{i j}^{\prime}=p_{j}^{\prime},(j=1,2, \cdots,|l(p)|)$.

Base on the weight joint distribution law, the weighted except mean $E_{w}(A B)$ related to the multiply of $A B$ can be obtained as follows.

Table 5. Weight joint distribution law between $A_{w}$ and $B_{w^{\prime}}$.

\begin{tabular}{cccccccc}
\hline & $w_{1}^{\prime} \gamma_{1}^{\prime}$ & $w_{2}^{\prime} \gamma_{2}^{\prime}$ & $\cdots$ & $w_{j}^{\prime} \gamma_{j}^{\prime}$ & $\cdots$ & $w_{|l(p)|}^{\prime} \gamma_{|l(p)|}^{\prime}$ & $p_{i} \cdot$ \\
\hline$w_{1} \gamma_{1}$ & $p_{11}^{\prime}$ & $p_{12}^{\prime}$ & $\cdots$ & $p_{1 j}^{\prime}$ & $\cdots$ & $p_{1|l(p)|}^{\prime}$ & $p_{1}$ \\
$w_{2} \gamma_{2}$ & $p_{21}^{\prime}$ & $p_{22}^{\prime}$ & $\cdots$ & $p_{2 j}^{\prime}$ & $\cdots$ & $p_{2|l(p)|}^{\prime}$ & $p_{2}$ \\
$\vdots$ & $\vdots$ & $\vdots$ & $\vdots$ & $\vdots$ & $\vdots$ & $\vdots$ & $\vdots$ \\
$w_{i} \gamma_{i}$ & $p_{i 1}^{\prime}$ & $p_{i 2}^{\prime}$ & $\cdots$ & $p_{i j}^{\prime}$ & $\cdots$ & $p_{i|l(p)|}^{\prime}$ & $p_{i}$ \\
$\vdots$ & $\vdots$ & $\vdots$ & $\vdots$ & $\vdots$ & $\vdots$ & $\vdots$ & $\vdots$ \\
$w_{|h(p)| \gamma_{|h(p)|}}$ & $p_{|h(p)| 1}^{\prime}$ & $p_{|h(p)| 2}^{\prime}$ & $\cdots$ & $p_{|h(p)| j}^{\prime}$ & $\cdots$ & $p_{|h(p)||l(p)|}^{\prime}$ & $p_{|h(p)|}^{\prime}$ \\
$p_{\cdot j}$ & $p_{1}^{\prime}$ & $p_{2}^{\prime}$ & $\cdots$ & $p_{j}^{\prime}$ & $\cdots$ & $p_{|l(p)|}^{\prime}$ & 1 \\
\hline
\end{tabular}


Definition 13. Let $A_{w}$ and $B_{w^{\prime}}$ be two WPHFEs, the weighted expect mean between them is obtained as:

$$
E_{w}(A B)=\sum_{i=1}^{|h(p)|} \sum_{j=1}^{|l(p)|} w_{i} w_{j}^{\prime} \gamma_{i} \gamma_{j}^{\prime} p_{i j}^{\prime} .
$$

Using Definitions 11 and 13, the weighted covariance between two WPHFEs can be derived as follows.

Definition 14. Let $A_{w}$ and $B_{w^{\prime}}$ be two WPHFEs, the weighted covariance between them is obtained as:

$$
\operatorname{Cov}_{w}(A, B)=E\left(A-E_{w}(A)\right)\left(B-E_{w^{\prime}}(B)\right) .
$$

Using Definitions 13 and 15, the weighted correlation coefficient between two WPHFEs can be calculated as follows.

Definition 15. Let $A_{w}$ and $B_{w^{\prime}}$ be two WPHFEs, the weighted correlation coefficient between them is obtained as:

$$
\rho_{w}(A, B)=\frac{E\left(A-E_{w}(A)\right)\left(B-E_{w^{\prime}}(B)\right)}{\sqrt{D_{w}(A)} \sqrt{D_{w^{\prime}}(B)}} .
$$

The weighted correlation coefficient obtained in Equation (16) has the following properties.

Property 3. For any WPHFEs $A_{w}$ and $B_{w^{\prime}}$, the weighted correlation coefficient obtained in Equation (16) satisfies:

(1) $\rho_{w}(A, B)=\rho_{w}(B, A)$;

(2) $\quad-1 \leq \rho_{w}(A, B) \leq 1$;

(3) if $A_{w}=B_{w^{\prime}} \Rightarrow \rho_{w}(A, B)=1$.

The proof of Property 3 is similar to the proof of Property 2, so it has been omitted here.

\section{Multi-Criteria Decision-Making Based on Probabilistic Hesitant Fuzzy Information}

In this section, a MCDM problems within probabilistic hesitant fuzzy environment is adopted to demonstrate how to apply the proposed method.

\subsection{Problems Description}

For a MCDM problems, let $A=\left\{A_{1}, A_{2}, \cdots, A_{n}\right\}$ be a set of alternatives, $G=\left\{G_{1}, G_{2}, \cdots, G_{m}\right\}$ be a set of criteria, the criteria weights are completely unknown. Assume the criteria are independent to each other. $D=\left\{D_{1}, D_{2}, \cdots, D_{t}\right\}$ be a set of decision makers. And the evaluation of the alternative $A_{j}$ with respect to the criterion $G_{i}$ is represent in PHFEs.

The MCDM processes designed to find the best alternative is given by the following steps:

Step 1: Construct individual probabilistic hesitant fuzzy decision matrix

The individual probabilistic hesitant fuzzy decision matrix can be constructed and denoted as $D^{k}=\left(\gamma_{i j}\left(p_{i j}\right)^{k}\right)_{m \times n^{\prime}}$;

Step 2: Integrate individual probabilistic hesitant fuzzy decision matrix into one

Use Equation (6) to integrate individual probabilistic hesitant fuzzy decision matrix into an overall decision matrix and denotes as $D=\left(\gamma_{i j}\left(p_{i j}\right)\right)_{m \times n^{\prime}}$;

Step 3: Derive the criteria weights 
The criteria weights can be derived utilizing the following formula:

$$
w_{i}=\frac{\sum_{j=1}^{n} E\left(\gamma_{i j}\left(p_{i j}\right)\right)}{\sum_{j=1}^{n} \sum_{i=1}^{m} E\left(\gamma_{i j}\left(p_{i j}\right)\right)},(i=1,2, \cdots, m) .
$$

Step 4: Calculate the weighted correlation coefficient

By applying Equation (12), the ideal alternative $A^{*}$ under the criterion $G_{i}$ can be obtained as follows:

$$
A^{*}=\max \left\{A_{j} \mid w_{i} \gamma_{i j} p_{i j}, i=1,2, \cdots, m ; j=1,2, \cdots, n\right\} .
$$

Here, the weighted of $w_{i}$ is obtained from Equation (17).

And then calculate the weighted correlation coefficient between any alternative $A$ and ideal alternative $A^{*}$.

Use Equation (16), calculate the weighted correlation coefficient between $A$ and $A^{*}$ as follows:

$$
\rho_{w}\left(A, A^{*}\right)=\frac{E\left(A-E_{w}(A)\right)\left(A^{*}-E_{w^{\prime}}\left(A^{*}\right)\right)}{\sqrt{D_{w}(A)} \sqrt{D_{w^{\prime}}\left(A^{*}\right)}} .
$$

Step 5: Rank all alternatives

Since the higher the score of the weighted correlation coefficient obtain from Equation (19), means that the more similarity between any alternative $A$ and the ideal alternative $A^{*}$, the better the alternative $A$ is. Based on this consideration, the ranking result of the alternatives $A_{j},(j=1,2, \cdots, n)$ can be obtained according to the following formula:

$$
r_{j}=\sum_{i=1}^{m} \beta_{i j},(j=1,2, \cdots, n)
$$

Here, $\beta_{i j}$ is the value of weighted correlation coefficient, obtained from Step 4.

\subsection{Illustrative Example}

Suppose there is an investment company, which wants to invest a sum of money in the best option, there is a panel with four possible alternatives to invest: (1) $A_{1}$ is a car company; (2) $A_{2}$ is a food company; (3) $A_{3}$ is a computer company; (4) $A_{4}$ is an arms company. The investment company must take a decision according to the following five criteria: (1) $G_{1}$ is the productivity; (2) $G_{2}$ is the technological innovation capability; (3) $G_{3}$ is the marketing capability; (4) $G_{4}$ is the management; (5) $G_{5}$ is the risk avoidance.

An expert group is formed which consists of four experts $D_{t}(t=1,2,3,4)$ from each strategic decision area (whose weight vector is equally). Suppose each expert consulted 10 people in the same industry through online questionnaire and the 10 people they consulted were not exactly similar. Four experts provided their preference evaluations on alternatives in the form of PHFEs, as shown in Tables 6-9, respectively. Take the evaluation values $\{0.6(0.4), 0.7(0.6)\}$ from Expert 1, for example, evaluation information is obtained from 10 people related to computer company $A_{3}$ with respect to productivity $G_{1}$. Four of them set a value of 0.6 , whereas six of them set a value 0.7 and thus, the probability of the vale 0.6 is 0.4 and the probability of the vale 0.7 is 0.6 . Other entries, that is, other PHFEs, in Tables 6-9 can be similarly explained. Because four experts consulted the people in the same industry may be communicate with each other, in this case, the evaluation information obtained from four experts are interact with each other. 
Table 6. The evaluation information provided from $D_{1}$.

\begin{tabular}{ccccc}
\hline & $A_{\mathbf{1}}$ & $\boldsymbol{A}_{\mathbf{2}}$ & $\boldsymbol{A}_{\mathbf{3}}$ & $\boldsymbol{A}_{\mathbf{4}}$ \\
\hline$G_{1}$ & 0.5 & 0.3 & $\{0.6(0.4), 0.7(0.6)\}$ & 0.4 \\
$G_{2}$ & 0.7 & 0.4 & $\{0.4(0.5), 0.5(0.5)\}$ & 0.3 \\
$G_{3}$ & $\{0.4(0.4), 0.3(0.6)\}$ & $\{0.6(0.5), 0.5(0.5)\}$ & 0.3 & 0.5 \\
$G_{4}$ & 0.6 & 0.7 & 0.3 & 0.5 \\
$G_{5}$ & 0.5 & 0.6 & 0.4 & $\{0.4(0.5), 0.5(0.5)\}$ \\
\hline
\end{tabular}

Table 7. The evaluation information provided from $D_{2}$.

\begin{tabular}{lllll}
\hline & $A_{\mathbf{1}}$ & $\boldsymbol{A}_{\mathbf{2}}$ & $\boldsymbol{A}_{\mathbf{3}}$ & $\boldsymbol{A}_{\mathbf{4}}$ \\
\hline$G_{1}$ & 0.5 & 0.4 & 0.6 & 0.3 \\
$G_{2}$ & 0.6 & 0.5 & 0.6 & 0.4 \\
$G_{3}$ & 0.4 & 0.4 & 0.5 & 0.5 \\
$G_{4}$ & 0.7 & 0.6 & 0.3 & 0.5 \\
$G_{5}$ & 0.3 & 0.6 & 0.4 & 0.7 \\
\hline
\end{tabular}

Table 8. The evaluation information provided from $D_{3}$.

\begin{tabular}{ccccc}
\hline & $A_{\mathbf{1}}$ & $A_{\mathbf{2}}$ & $A_{\mathbf{3}}$ & $A_{\mathbf{4}}$ \\
\hline$G_{1}$ & 0.5 & $\{0.2(0.4), 0.3(0.6)\}$ & $\{0.6(0.4), 0.7(0.6)\}$ & 0.6 \\
$G_{2}$ & $\{0.8(0.4), 0.7(0.6)\}$ & 0.4 & $\{0.4(0.5), 0.5(0.5)\}$ & 0.3 \\
$G_{3}$ & 0.4 & 0.5 & 0.6 & $\{0.4(0.5), 0.3(0.5)\}$ \\
$G_{4}$ & 0.7 & 0.4 & 0.5 & $\{0.4(0.7), 0.5(0.3)\}$ \\
$G_{5}$ & 0.4 & 0.6 & 0.7 & 0.2 \\
\hline
\end{tabular}

Table 9. The evaluation information provided from $D_{4}$.

\begin{tabular}{ccccc}
\hline & $A_{\mathbf{1}}$ & $\boldsymbol{A}_{\mathbf{2}}$ & $\boldsymbol{A}_{\mathbf{3}}$ & $\boldsymbol{A}_{\mathbf{4}}$ \\
\hline$G_{1}$ & 0.7 & 0.3 & 0.4 & 0.2 \\
$G_{2}$ & 0.7 & 0.5 & 0.5 & 0.6 \\
$G_{3}$ & 0.6 & 0.8 & 0.2 & $\{0.4(0.5), 0.3(0.5)\}$ \\
$G_{4}$ & $\{0.4(0.5), 0.3(0.5)\}$ & $\{0.7(0.5), 0.6(0.5)\}$ & 0.1 & 0.6 \\
$G_{5}$ & 0.8 & 0.4 & $\{0.7(0.5), 0.6(0.5)\}$ & 0.5 \\
\hline
\end{tabular}

The processes are designed to find the best alternative is given by the following steps:

Step 1: Construct individual probabilistic hesitant fuzzy decision matrix

The individual probabilistic hesitant fuzzy decision matrix has been constructed and is shown in Tables 6-9.

Step 2: Integrate individual probabilistic hesitant fuzzy decision matrix

Use Equation (7) to integrate individual probabilistic hesitant fuzzy decision matrix into an overall decision matrix and is shown in Table 10.

Step 3: Derive the criteria weights

By applying Equation (17), the weights of criteria are calculated as follows:

$$
w_{1}=0.19, w_{2}=0.21, w_{3}=0.19, w_{4}=0.20 \text { and } w_{5}=0.21 \text {. }
$$

Step 4: Calculate the weighted correlation coefficient

By applying Equation (19), the weighted correlation coefficient can be obtained and is shown in Table 11. 
Table 10. Integrate individual evaluation information.

\begin{tabular}{|c|c|c|c|c|}
\hline & $A_{1}$ & $A_{2}$ & $A_{3}$ & $A_{4}$ \\
\hline \multirow{2}{*}{$G_{1}$} & & $0.2(0.1), 0.3(0.65)$ & $0.4(0.25), 0.6(0.45)$ & $0.2(0.25), 0.3(0.25)$ \\
\hline & $\{0.5(0.75), 0.7(0.25)\}$ & $0.4(0.25)$ & $0.7(0.3)$ & $0.4(0.25), 0.6(0.25)$ \\
\hline$G_{2}$ & $\begin{array}{c}0.6(0.25), 0.7(0.65) \\
0.8(0.1)\end{array}$ & $\{0.4(0.5), 0.5(0.5)\}$ & $\begin{array}{c}0.4(0.25), 0.5(0.5) \\
0.6(0.25)\end{array}$ & $\begin{array}{c}0.3(0.5), 0.4(0.25) \\
0.6(0.25)\end{array}$ \\
\hline \multirow{2}{*}{$G_{3}$} & $0.3(0.15), 0.4(0.6)$ & $0.4(0.25), 0$ & $0.2(0.25), 0.3(0.25)$ & $0.3(0.25), 0.4(0.25)$ \\
\hline & $0.6(0.25)$ & $0.6(0.125), 0.8(0.25)$ & $0.5(0.25), 0.6(0.25)$ & $0.5(0.5)$ \\
\hline \multirow{2}{*}{$G_{4}$} & $0.3(0.125), 0.4(0.125)$ & $0.4(0.25), 0.6(0.375)$ & $0.1(0.25), 0.3(0.5)$ & $0.4(0.175), 0.6(0.25)$ \\
\hline & $0.6(0.25), 0.7(0.5)$ & $0.7(0.375)$ & $0.5(0.25)$ & $0.5(0.575)$ \\
\hline \multirow{2}{*}{$G_{5}$} & $0.3(0.25), 0.4(0.25)$ & $\{0.6(0.75), 0.4(0.25)\}$ & $0.4(0.5), 0.6(0.125)$ & $0.2(0.25), 0.5(0.325)$ \\
\hline & $0.5(0.25), 0.8(0.25)$ & $\{0.6(0 . / 5), 0.4(0.25)\}$ & $0.7(0.375)$ & $0.4(0.125), 0.7(0.25)$ \\
\hline
\end{tabular}

Table 11. Weight correlation coefficient.

\begin{tabular}{ccccc}
\hline & $\rho_{w}\left(A_{\mathbf{1}}, A^{*}\right)$ & $\rho_{w}\left(A_{\mathbf{2}}, A^{*}\right)$ & $\rho_{w}\left(A_{\mathbf{3}}, A^{*}\right)$ & $\rho_{w}\left(A_{\mathbf{4}}, A^{*}\right)$ \\
\hline$G_{1}$ & 0.62 & 0.75 & 1 & 0.28 \\
$G_{2}$ & 1 & 0.61 & 0.86 & 0.64 \\
$G_{3}$ & 0.94 & 1 & 0.9 & -0.03 \\
$G_{4}$ & 0.95 & 1 & 0.91 & 0.27 \\
$G_{5}$ & -0.93 & 1 & -0.67 & -0.74 \\
\hline
\end{tabular}

Step 5: Rank all alternatives.

The ranking result of the alternatives $A_{j}(j=1,2, \cdots, 4)$ can be obtained according to the Formula (20) as follows:

$$
r_{1}=2.28, r_{2}=4.36, r_{3}=3, r_{4}=0.42
$$

Since $r_{2}>r_{3}>r_{1}>r_{4}$, then $A_{2} \succ A_{3} \succ A_{1} \succ A_{4}$. Hence, the most desirable alternative is $A_{2}$. That is, the food company is the best option to invest.

It is stated that in this example, the correlation coefficient is proposed in this paper lies in the interval $[-1,1]$, which not only consider the strength of relationship between the PHFSs but also whether the PHFSs are positively or negatively related. In this illustrative example, we can also use the methods proposed in $[8,36]$ to solve the problem illustrative in the example. However, the method proposed in [36] directly integrated the probability part into the membership degree part, this make cause a lot of information loss. For example, the positively or negatively related obtained from the proposed method. And the method proposed in [8] fail in the condition when two PHFEs are not mutual independent.

\section{Conclusions}

This article puts forward a framework to tackle MCDM problems within probabilistic hesitant fuzzy environments with completely unknown criteria weight information. Since every PHFE consists of two parts, that is, the membership degree of the element to the set and the corresponding probability of the membership degree, this information can be treated as a probabilistic distribution function, inspired by statistics knowledge, each PHFE can be regarded as a discrete random variable. The primary contributions of this paper are summarized as follows. (1) The correlation coefficient is proposed in this paper adopt the knowledge of statistics, the significant characteristic of the proposed formula is that it lies in the interval $[-1,1]$. The proposed formula not only consider the strength of the PHFSs but also whether the PHFSs are positively or negatively related, it avoids the inconsistency of the decision-making result due to the loss of information; (2) The existing decision-making methods related to probabilistic hesitant fuzzy environments, very few papers discussed the condition when two random variables are not mutual independent. In this paper, the northwest corner rule to obtain the expected mean of two PHFEs multiply is introduced; (3) A novel MCDM method with the probabilistic 
hesitant fuzzy environment is introduced based on the proposed weighted correlation coefficient and this proposed method is applied to practical decision-making processes.

In this paper, we have applied the proposed correlation coefficient in evaluation of the alternatives. In the future, we will apply it in other aspects, such as, pattern recognition and cluster analysis. In addition, in this paper, we only discuss the correlation coefficients between two PHFSs, in future study, the proposed correlation coefficients will be extended to other extension of PHFSs, such as, interval-valued probabilistic hesitant fuzzy sets, probabilistic linguistic term sets and so on.

Acknowledgments: The authors thank the editors and anonymous reviewers for providing very thoughtful comments which have leaded to an improved version of this paper.

Author Contributions: All authors have contributed equally to this paper.

Conflicts of Interest: The authors declare no conflict of interest.

\section{Appendix A. Proof of Property 1}

Proof. The proof of (1), (2) and (3) is obvious, so it has been omitted here. And the proof of (4) will be demonstrated as follows:

Suppose $h_{A}\left(p_{A}\right)$ has only one element in it, denoted by $h_{A}\left(p_{A}\right)=\left\{h_{1}\left(p_{1}\right)\right\}$, according to Definition 3, we have $p_{1}=1$. Let $h_{B}\left(p_{B}\right)=\left\{\gamma_{j}^{\prime}\left(p_{j}^{\prime}\right)|j=1,2, \cdots| l,(p) \mid\right\}$, utilizing the northwest corner rule, the joint distribution law between them can be determined and is shown in Table A1.

Table A1. Joint distribution law between $h_{A}\left(p_{A}\right)$ and $h_{B}\left(p_{B}\right)$ in Property 1.

\begin{tabular}{cccccccc}
\hline & $\gamma_{1}^{\prime}$ & $\gamma_{2}^{\prime}$ & $\cdots$ & $\gamma_{j}^{\prime}$ & $\cdots$ & $\gamma_{|l(p)|}^{\prime}$ & $p_{i} \cdot$ \\
\hline$\gamma_{1}$ & $p_{1}^{\prime}$ & $p_{2}^{\prime}$ & $\cdots$ & $p_{j}^{\prime}$ & $\cdots$ & $p_{|l(p)|}^{\prime}$ & $p_{1}$ \\
$p \cdot j$ & $p_{1}^{\prime}$ & $p_{2}^{\prime}$ & $\cdots$ & $p_{j}^{\prime}$ & $\cdots$ & $p_{|l(p)|}^{\prime}$ & 1 \\
\hline
\end{tabular}

According to Definition 8, we have

$$
\begin{aligned}
E(A B) & =\gamma_{1} \gamma_{1}^{\prime} p_{1}^{\prime}+\gamma_{1} \gamma_{2}^{\prime} p_{2}^{\prime}+\cdots+\gamma_{1} \gamma_{|l(p)|}^{\prime} p_{|l(p)|}^{\prime} \\
& =\gamma_{1}\left(\gamma_{1}^{\prime} p_{1}^{\prime}+\gamma_{2}^{\prime} p_{2}^{\prime}+\cdots+\gamma_{|l(p)|}^{\prime} p_{|l(p)|}^{\prime}\right) \\
& =\gamma_{1} p_{1}\left(\gamma_{1}^{\prime} p_{1}^{\prime}+\gamma_{2}^{\prime} p_{2}^{\prime}+\cdots+\gamma_{|l(p)|}^{\prime} p_{|l(p)|}^{\prime}\right) \\
& =E(A) E(B) .
\end{aligned}
$$

Therefore, we have $\operatorname{Cov}=E(A-E(A))(B-E(B))=E(A B)-E(A) E(B)=0$. The similar proof can be obtained if $h_{B}\left(p_{B}\right)$ has only one element in it.

This completes the proof.

\section{Appendix B. Proof of Property 2}

\section{Proof.}

(1) It is straightforward.

(2) According to Property 1, we have

$$
\operatorname{Cov}(A, B)=E(A B)-E(A) E(B)=E(A-E(A))(B-E(B)),
$$


and

$$
\begin{aligned}
& E(A-E(A))(B-E(B))=\sum_{i=1}^{|h(p)|} \sum_{j=1}^{|l(p)|}\left(\gamma_{i}-E(A)\right)\left(\gamma_{j}^{\prime}-E(B)\right) p_{i j} \\
& =\sum_{j=1}^{|l(p)|}\left(\gamma_{1}-E(A)\right)\left(\gamma_{j}^{\prime}-E(B)\right) p_{1 j}+\sum_{j=1}^{|l(p)|}\left(\gamma_{2}-E(A)\right)\left(\gamma_{j}^{\prime}-E(B)\right) p_{2 j} \\
& +\cdots+\sum_{j=1}^{|l(p)|}\left(\gamma_{|h(p)|}-E(A)\right)\left(\gamma_{j}^{\prime}-E(B)\right) p_{|h(p)| j} \\
& =\sum_{j=1}^{|l(p)|}\left(\gamma_{1}-E(A)\right) \sqrt{p_{1 j}}\left(\gamma_{j}^{\prime}-E(B)\right) \sqrt{p_{1 j}}+\sum_{j=1}^{l l(p) \mid}\left(\gamma_{2}-E(A)\right) \sqrt{p_{2 j}}\left(\gamma_{j}^{\prime}-E(B)\right) \sqrt{p_{2 j}} \\
& +\cdots+\sum_{j=1}^{|l(p)|}\left(\gamma_{|h(p)|}-E(A)\right) \sqrt{p_{|h(p)| j}}\left(\gamma_{j}^{\prime}-E(B)\right) \sqrt{p_{|h(p)| j}} .
\end{aligned}
$$

Using the Cauchy-Schwarz inequality $\left(a_{1}^{2}+a_{2}^{2}+\cdots+a_{n}^{2}\right)\left(b_{1}^{2}+b_{2}^{2}+\cdots+b_{n}^{2}\right)$, it follows that

$$
\begin{aligned}
& {[\operatorname{Cov}(A, B)]^{2}=\left[\sum_{i=1}^{|h(p)||l(p)|} \sum_{j=1}\left(\gamma_{i}-E(A)\right)\left(\gamma_{j}^{\prime}-E(B)\right) p_{i j}\right]^{2}} \\
& \leq\left[\sum_{j=1}^{|l(p)|}\left(\gamma_{1}-E(A)\right)^{2} p_{1 j}+\sum_{j=1}^{|l(p)|}\left(\gamma_{2}-E(A)\right)^{2} p_{2 j}+\cdots+\sum_{j=1}^{|l(p)|}\left(\gamma_{|h(p)|}-E(A)\right)^{2} p_{|h(p)| j}\right] \\
& \times\left[\sum_{j=1}^{|l(p)|}\left(\gamma_{j}^{\prime}-E(B)\right)^{2} p_{1 j}+\sum_{j=1}^{|l(p)|}\left(\gamma_{j}^{\prime}-E(B)\right)^{2} p_{2 j}+\cdots+\sum_{j=1}^{|l(p)|}\left(\gamma_{j}^{\prime}-E(B)\right)^{2} p_{|h(p)| j}\right] \\
& =\left[\left(\gamma_{1}-E(A)\right)^{2} \sum_{j=1}^{|l(p)|} p_{1 j}+\left(\gamma_{2}-E(A)\right)^{2} \sum_{j=1}^{|l(p)|} p_{2 j}+\cdots+\left(\gamma_{|h(p)|}-E(A)\right)^{2} \sum_{j=1}^{|l(p)|} p_{|h(p)| j}\right] \\
& \times\left[\left(\gamma_{1}^{\prime}-E(B)\right)^{2} \sum_{i=1}^{|h(p)|} p_{i 1}+\left(\gamma_{2}^{\prime}-E(B)\right)^{2} \sum_{i=1}^{|h(p)|} p_{i 2}+\cdots+\left(\gamma_{|l(p)|}^{\prime}-E(B)\right)^{2} \sum_{i=1}^{|h(p)|} p_{i|l(p)|}\right] \\
& =\left[\left(\gamma_{1}-E(A)\right)^{2} p_{1}+\left(\gamma_{2}-E(A)\right)^{2} p_{2}+\cdots+\left(\gamma_{|h(p)|}-E(A)\right)^{2} p_{|h(p)|}\right] \\
& \times\left[\left(\gamma_{1}^{\prime}-E(B)\right)^{2} p_{1}^{\prime}+\left(\gamma_{2}^{\prime}-E(B)\right)^{2} p_{2}^{\prime}+\cdots+\left(\gamma_{|l(p)|}^{\prime}-E(B)\right)^{2} p_{|l(p)|}^{\prime}\right] \\
& =\left[\sum_{i=1}^{|h(p)|}\left(\gamma_{i}-E(A)\right)^{2} p_{i}\right] \times\left[\sum_{j=1}^{|l(p)|}\left(\gamma_{j}^{\prime}-E(B)\right)^{2} p_{j}^{\prime}\right] .
\end{aligned}
$$

Taking the square root of both sides, this inequality reduces to:

$$
\left|\sum_{i=1}^{|h(p)|} \sum_{j=1}^{|l(p)|}\left(\gamma_{i}-E(A)\right)\left(\gamma_{j}^{\prime}-E(B)\right) p_{i j}\right| \leq\left[\sum_{i=1}^{|h(p)|}\left(\gamma_{i}-E(A)\right)^{2} p_{i}\right]^{\frac{1}{2}} \times\left[\sum_{j=1}^{|l(p)|}\left(\gamma_{j}^{\prime}-E(B)\right)^{2} p_{j}^{\prime}\right]^{\frac{1}{2}}
$$

Therefore, this inequality can be rewritten as:

$$
\frac{\left|\sum_{i=1}^{|h(p)||l(p)|} \sum_{j=1}\left(\gamma_{i}-E(A)\right)\left(\gamma_{j}^{\prime}-E(B)\right) p_{i j}\right|}{\sqrt{\sum_{i=1}^{|h(p)|}\left(\gamma_{i}-E(A)\right)^{2} p_{i}} \times \sqrt{\sum_{j=1}^{|l(p)|}\left(\gamma_{j}^{\prime}-E(B)\right)^{2} p_{j}^{\prime}}} \leq 1 .
$$

Therefore, we have $-1 \leq \rho(A, B) \leq 1$.

(3) if $h_{A}\left(p_{A}\right)=h_{B}\left(p_{B}\right) \Rightarrow \gamma_{i}=\gamma_{j}^{\prime}, p_{i}=p_{j}^{\prime}$ and $|h(p)|=|l(p)|$, utilizing the northwest corner rule, the joint distribution law between them can be determined and is shown in Table A2. 
Table A2. Joint distribution law between $h_{A}\left(p_{A}\right)$ and $h_{A}\left(p_{A}\right)$ in Property 2.

\begin{tabular}{cccccccc}
\hline & $\gamma_{1}$ & $\gamma_{2}$ & $\cdots$ & $\gamma_{i}$ & $\cdots$ & $\gamma_{|h(p)|}$ & $p_{i} \cdot$ \\
\hline$\gamma_{1}$ & $p_{1}$ & 0 & $\cdots$ & 0 & $\cdots$ & 0 & $p_{1}$ \\
$\gamma_{2}$ & 0 & $p_{2}$ & $\cdots$ & 0 & $\cdots$ & 0 & $p_{2}$ \\
$\vdots$ & $\vdots$ & $\vdots$ & $\vdots$ & $\vdots$ & $\vdots$ & $\vdots$ & $\vdots$ \\
$\gamma_{i}$ & 0 & 0 & $\cdots$ & $p_{i}$ & $\cdots$ & 0 & $p_{i}$ \\
$\vdots$ & $\vdots$ & $\vdots$ & $\vdots$ & $\vdots$ & $\vdots$ & $\vdots$ & $\vdots$ \\
$\gamma_{|h(p)|}$ & 0 & 0 & $\cdots$ & 0 & $\cdots$ & $p_{|h(p)|}$ & $p_{|h(p)|}$ \\
$p_{j} j$ & $p_{1}$ & $p_{2}$ & $\cdots$ & $p_{i}$ & $\cdots$ & $p_{|h(p)|}$ & 1 \\
\hline
\end{tabular}

And

$$
\begin{gathered}
E\left(A^{2}\right)=\gamma_{1}^{2} p_{1}+\gamma_{2}^{2} p_{2}+\cdots+\gamma_{|h(p)|}^{2} p_{|h(p)|} \\
E(A)=\gamma_{1} p_{1}+\gamma_{2} p_{2}+\cdots+\gamma_{|h(p)|} p_{|h(p)|}
\end{gathered}
$$

Thus, we have

$$
\begin{aligned}
& \operatorname{Cov}(A, A)=E\left(A^{2}\right)-E(A)^{2} \\
& =\gamma_{1}^{2} p_{1}+\gamma_{2}^{2} p_{2}+\cdots+\gamma_{|h(p)|}^{2} p_{|h(p)|}-\left(\gamma_{1} p_{1}+\gamma_{2} p_{2}+\cdots+\gamma_{|h(p)|} p_{|h(p)|}\right)^{2} \\
& =D(A) .
\end{aligned}
$$

Thus, we have

$$
\rho(A, A)=1 .
$$

(4) If $h_{B}\left(p_{B}\right)=h_{A}\left(p_{A}\right)^{c}$, according to the supplement operation law was introduced in [41], we obtain: $h_{A}\left(p_{A}\right)^{c}=\left\{\left(1-\gamma_{i}\right)\left(p_{i}\right)|i=1,2, \cdots| h,(p) \mid\right\}$, utilizing the northwest corner rule, the joint distribution law between them can be determined and is shown in Table A3.

And

Since

$$
\begin{aligned}
& E\left(A^{c}\right)=\left(1-\gamma_{1}\right) p_{1}+\left(1-\gamma_{2}\right) p_{2}+\cdots+\left(1-\gamma_{|h(p)|}\right) p_{|h(p)|} \\
& =p_{1}-\gamma_{1} p_{1}+p_{2}-\gamma_{2} p_{2}+\cdots+p_{|h(p)|}-\gamma_{|h(p)|} p_{|h(p)|} \\
& =p_{1}+p_{2}+\cdots+p_{|h(p)|}-\left(\gamma_{1} p_{1}+\gamma_{2} p_{2}+\cdots+\gamma_{|h(p)|} p_{|h(p)|}\right) \\
& =1-E(A) .
\end{aligned}
$$

Thus, we have

$$
\begin{aligned}
& \operatorname{Cov}\left(A, A^{c}\right)=E\left(A A^{c}\right)-E(A) E\left(A^{c}\right) \\
& =E(A)-E\left(A^{2}\right)-E(A)(1-E(A)) \\
& =-E\left(A^{2}\right)+E(A)^{2} .
\end{aligned}
$$




$$
\begin{aligned}
\text { for } & D(A)=\gamma_{1}^{2} p_{1}+\gamma_{2}^{2} p_{2}+\cdots+\gamma_{|h(p)|}^{2} p_{|h(p)|}-E(A)^{2}=E\left(A^{2}\right)-E(A)^{2} . \\
& D\left(A^{c}\right)=\left(1-\gamma_{1}\right)^{2} p_{1}+\left(1-\gamma_{2}\right)^{2} p_{2}+\cdots+\left(1-\gamma_{|h(p)|}\right)^{2} p_{|h(p)|}-(1-E(A))^{2} \\
= & p_{1}-2 \gamma_{1} p_{1}+\gamma_{1}^{2} p_{1}+p_{2}-2 \gamma_{2} p_{2}+\gamma_{2}^{2} p_{2}+\cdots+p_{|h(p)|}-2 \gamma_{|h(p)|} p_{|h(p)|}+\gamma_{|h(p)|}^{2} p_{|h(p)|}-(1-E(A))^{2} \\
= & p_{1}+p_{2}+\cdots+p_{|h(p)|}-2\left(\gamma_{1} p_{1}+\gamma_{2} p_{2}+\cdots+\gamma_{|h(p)|} p_{|h(p)|}\right)+\gamma_{1}^{2} p_{1}+\gamma_{2}^{2} p_{2}+\cdots+\gamma_{|h(p)|}^{2} p_{|h(p)|}-(1-E(A))^{2} \\
= & 1-2 E(A)+E\left(A^{2}\right)-(1-E(A))^{2} \\
= & E\left(A^{2}\right)-E(A)^{2} .
\end{aligned}
$$

Thus, we have

$$
\rho\left(A, A^{c}\right)=\frac{\operatorname{Cov}\left(A, A^{c}\right)}{\sqrt{D(A)} \sqrt{D\left(A^{c}\right)}}=\frac{-E^{2}(A)+E(A)^{2}}{\sqrt{E\left(A^{2}\right)-E(A)^{2}} \sqrt{E\left(A^{2}\right)-E(A)^{2}}}=-1 .
$$

This completes the proof.

Table A3. Joint distribution law between $h_{A}\left(p_{A}\right)$ and $h_{A}\left(p_{A}\right)^{c}$ in Property 2.

\begin{tabular}{cccccccc}
\hline & $\mathbf{1}-\gamma_{\mathbf{1}}$ & $\mathbf{1}-\gamma_{\mathbf{2}}$ & $\cdots$ & $\mathbf{1}-\gamma_{\boldsymbol{i}}$ & $\cdots$ & $\mathbf{1}-\gamma_{|h(p)|}$ & $\boldsymbol{p}_{\boldsymbol{i}} \cdot$ \\
\hline$\gamma_{1}$ & $p_{1}$ & 0 & $\cdots$ & 0 & $\cdots$ & 0 & $p_{1}$ \\
$\gamma_{2}$ & 0 & $p_{2}$ & $\cdots$ & 0 & $\cdots$ & 0 & $p_{2}$ \\
$\vdots$ & $\vdots$ & $\vdots$ & $\vdots$ & $\vdots$ & $\vdots$ & $\vdots$ & $\vdots$ \\
$\gamma_{i}$ & 0 & 0 & $\cdots$ & $p_{i}$ & $\cdots$ & 0 & $p_{i}$ \\
$\vdots$ & $\vdots$ & $\vdots$ & $\vdots$ & $\vdots$ & $\vdots$ & $\vdots$ & $\vdots$ \\
$\gamma_{|h(p)|}$ & 0 & 0 & $\cdots$ & 0 & $\cdots$ & $p_{|h(p)|}$ & $p_{|h(p)|}$ \\
$p{ }_{j}$ & $p_{1}$ & $p_{2}$ & $\cdots$ & $p_{i}$ & $\cdots$ & $p_{|h(p)|}$ & 1 \\
\hline
\end{tabular}

\section{References}

1. Sałabun, W.; Piegat, A. Comparative analysis of MCDM methods for the assessment of mortality in patients with acute coronary syndrome. Artif. Intell. Rev. 2016, 1-15. [CrossRef]

2. Anisseh, M.; Piri, F.; Shahraki, M.R.; Agamohamadi, F. Fuzzy extension of TOPSIS model for group decision making under multiple criteria. Artif. Intell. Rev. 2012, 38, 325-338. [CrossRef]

3. Sun, B.; Ma, W. Soft fuzzy rough sets and its application in decision making. Artif. Intell. Rev. 2014, 41, 67-80. [CrossRef]

4. Bashir, Z.; Wątróbski, J.; Rashid, T.; Sałabun, W.; Ali, J. Intuitionistic-Fuzzy goals in zero-sum multi criteria matrix games. Symmetry 2017, 9, 158. [CrossRef]

5. Liao, H.C.; Xu, Z.S. Consistency of the fused intuitionistic fuzzy preference relation in group intuitionistic fuzzy analytic hierarchy process. Appl. Soft Comput. 2015, 35, 812-826. [CrossRef]

6. Faizi, S.; Rashid, T.; Sałabun, W.; Zafar, S.; Wattróbski, J. Decision making with uncertainty using hesitant fuzzy sets. Int. J. Fuzzy Syst. 2017, 1-11. [CrossRef]

7. Faizi, S.; Sałabun, W.; Rashid, T.; Atróbski, J.W.; Zafar, S. Group decision-making for hesitant fuzzy sets based on characteristic objects method. Symmetry 2017, 9, 136. [CrossRef]

8. Alcantud, J.C.R.; Torra, V. Decomposition theorems and extension principles for hesitant fuzzy sets. Inf. Fusion 2018, 41, 48-56. [CrossRef]

9. Li, J.; Wang, J.Q. An extended QUALIFLEX method under probability hesitant fuzzy environment for selecting green suppliers. Int. J. Fuzzy Syst. 2017, 1-14. [CrossRef]

10. Zhu, B.; Xu, Z.S. Probability-hesitant fuzzy sets and the representation of preference relations. Technol. Econ. Dev. Econ. 2017, in press.

11. Pang, Q.; Wang, H.; Xu, Z.S. Probabilistic linguistic term sets in multi-attribute group decision making. Inf. Sci. 2016, 369, 128-143. [CrossRef]

12. Lv, Z.; Zhao, J.; Liu, Y.; Wang, W. Data imputation for gas flow data in steel industry based on non-equal-length granules correlation coefficient. Inf. Sci. 2016, 367-368, 311-323. [CrossRef] 
13. Bai, X.Z. Morphological center operator based infrared and visible image fusion through correlation coefficient. Infrared Phys. Technol. 2016, 76, 546-554. [CrossRef]

14. Rao, C.S.; Raju, S.V. Similarity analysis between chromosomes of Homo sapiens and monkeys with correlation coefficient, rank correlation coefficient and cosine similarity measures. Genom. Data 2016, 7, 202-209.

15. Yang, C.C. Correlation coefficient evaluation for the fuzzy interval data. J. Bus. Res. 2016, 69, $2138-2144$. [CrossRef]

16. Hong, D.H. Fuzzy measures for a correlation coefficient of fuzzy numbers under TW (the weakest t-norm)-based fuzzy arithmetic operations. Inf. Sci. 2006, 176, 150-160. [CrossRef]

17. Liu, S.T.; Kao, C. Fuzzy measures for correlation coefficient of fuzzy numbers. Inf. Sci. 2006, 128, $267-275$. [CrossRef]

18. Hung, W.L.; Wu, J.W. Correlation of intuitionistic fuzzy sets by centroid method. Inf. Sci. 2002, 144, $219-225$. [CrossRef]

19. Ye, J. Fuzzy decision-making method based on the weighted correlation coefficient under intuitionistic fuzzy environment. Eur. J. Oper. Res. 2010, 205, 202-204. [CrossRef]

20. Ye, J. Multicriteria fuzzy decision-making method using entropy weights-based correlation coefficients of interval-valued intuitionistic fuzzy sets. Appl. Math. Model. 2010, 34, 3864-3870. [CrossRef]

21. Dong, G.P.; Kwun, Y.C.; Jin, H.P.; Park, I.Y. Correlation coefficient of interval-valued intuitionistic fuzzy sets and its application to multiple attribute group decision making problems. Math. Comput. Model. Int. J. 2009, 50, 1279-1293.

22. Chen, N.; Xu, Z.S.; Xia, M.M. Correlation coefficients of hesitant fuzzy sets and their applications to clustering analysis. Appl. Math. Model. 2013, 37, 2197-2211. [CrossRef]

23. Liao, H.C.; Xu, Z.S.; Zeng, X.J. Novel correlation coefficients between hesitant fuzzy sets and their application in decision making. Knowl.-Based Syst. 2015, 82, 115-127. [CrossRef]

24. Liao, H.C.; Xu, Z.S.; Zeng, X.J. Qualitative decision making with correlation coefficients of hesitant fuzzy linguistic term sets. Knowl.-Based Syst. 2015, 76, 127-138. [CrossRef]

25. González-Arteaga, T.; Alcantud, J.C.R.; Andrés, R.D. New correlation coefficients for hesitant fuzzy sets. In Proceedings of the 2015 Conference of the International Fuzzy Systems Association and the European Society for Fuzzy Logic and Technology (IFSA-EUSFLAT), Gijon, Spain, 30 June-3 July 2015.

26. Ye, J. Correlation coefficient of dual hesitant fuzzy sets and its application to multiple attribute decision making. Appl. Math. Model. 2014, 38, 659-666. [CrossRef]

27. Şahin, R.; Liu, P.D. Correlation coefficient of single-valued neutrosophic hesitant fuzzy sets and its applications in decision making. Neural Comput. Appl. 2016, 7, 1387-1395. [CrossRef]

28. Zhang, H.Y.; Ji, P.; Wang, J.Q.; Chen, X.H. An Improved Weighted Correlation Coefficient Based on Integrated Weight for Interval Neutrosophic Sets and Its Application in Multi-criteria Decision-making Problems. Int. J. Comput. Intell. Syst. 2015, 8, 1027-1043. [CrossRef]

29. Karaaslan, F. Correlation coefficients of single-valued neutrosophic refined soft sets and their applications in clustering analysis. Neural Comput. Appl. 2015, 8, 2781-2793. [CrossRef]

30. Zhu, B. Decision Method for Research and Application Based on Preference Relation; Southeast University: Nanjing, China, 2014.

31. Zhang, S.; Xu, Z.S.; He, Y. Operations and integrations of probabilistic hesitant fuzzy information in decision making. Inf. Fusion 2017, 38, 1-11. [CrossRef]

32. He, Y.; Xu, Z.S.; Jiang, W.L. Probabilistic interval reference ordering sets in multi-criteria group decision making. Int. J. Uncertain. Fuzziness Knowl.-Based Syst. 2017, 25, 189-212. [CrossRef]

33. Abdullah, L.; Najib, L. A new type-2 fuzzy set of linguistic variables for the fuzzy analytic hierarchy process. Expert Syst. Appl. 2014, 41, 3297-3305. [CrossRef]

34. Gou, X.J.; Xu, Z.S. Novel basic operational laws for linguistic terms, hesitant fuzzy linguistic term sets and probabilistic linguistic term sets. Inf. Sci. 2016, 372, 407-427. [CrossRef]

35. Bai, C.Z.; Zhang, R.; Qian, L.X.; Wu, Y.N. Comparisons of probabilistic linguistic term sets for multi-criteria decision making. Knowl.-Based Syst. 2017, 119, 284-291. [CrossRef]

36. Zhou, W.; Xu, Z.S. Probability calculation and element optimization of probabilistic hesitant fuzzy preference relations based on expected consistency. IEEE Trans. Fuzzy Syst. 2017, PP, 1. [CrossRef]

37. Hung, W.L. Using statistical viewpoint in developing correlation of intuitionistic fuzzy sets. Int. J. Uncertain. Fuzziness Knowl.-Based Syst. 2001, 9, 509-516. [CrossRef] 
38. Klinz, B.; Woeginger, G.J. The Northwest corner rule revisited. Discret. Appl. Math. 2013, 159, $1284-1289$. [CrossRef]

39. Torra, V. Hesitant fuzzy sets. Int. J. Intell. Syst. 2010, 25, 529-539. [CrossRef]

40. Xia, M.M.; Xu, Z.S. Hesitant fuzzy information aggregation in decision making. Int. J. Approx. Reason. 2011, 52, 395-407. [CrossRef]

41. Xu, Z.S.; Zhou, W. Consensus building with a group of decision makers under the hesitant probabilistic fuzzy environment. Fuzzy Optim. Decis. Mak. 2016, 1-23. [CrossRef]

42. Li, J.; Wang, J.Q. Multi-criteria outranking methods with hesitant probabilistic fuzzy sets. Cogn. Comput. 2017, 9, 611-625. [CrossRef] 